\title{
Cosimo Amantonico - Bruno Pompili, Atto dovuto.
} Rimbaud. Illuminazioni

\section{Mario Richter}

\section{(2) OpenEdition}

Journals

\section{Edizione digitale}

URL: https://journals.openedition.org/studifrancesi/4767

DOI: $10.4000 /$ studifrancesi. 4767

ISSN: 2421-5856

\section{Editore}

Rosenberg \& Sellier

\section{Edizione cartacea}

Data di pubblicazione: 1 avril 2012

Paginazione: 174

ISSN: 0039-2944

\section{Notizia bibliografica digitale}

Mario Richter, «Cosimo Amantonico - Bruno Pompili, Atto dovuto. Rimbaud. Illuminazioni», Studi Francesi [Online], 166 (I | LVI) | 2012, online dal 30 novembre 2015, consultato il 19 novembre 2021. URL: http:// journals.openedition.org/studifrancesi/4767 ; DOI: https://doi.org/10.4000/studifrancesi.4767

Questo documento è stato generato automaticamente il 19 novembre 2021.

\section{(c) $(1) \&$}

Studi Francesi è distribuita con Licenza Creative Commons Attribuzione - Non commerciale - Non opere derivate 4.0 Internazionale. 


\title{
Cosimo Amantonico - Bruno Pompili, Atto dovuto. Rimbaud. Illuminazioni
}

\author{
Mario Richter
}

\section{NOTIZIA}

COSIMO AMANTONICO - BRUNO POMPILI, Atto dovuto. Rimbaud. Illuminazioni, Gorgonzola, Edizioni B.A. Graphis, 2011, pp. 142.

1 È noto che Paul Verlaine ammetteva una lettura diversa del suo nome anagrammandolo in Pauvre Lelian. Si sa che Mallarmé, come scrive Pompili (noto studioso del Surrealismo) nel suo iniziale saggio che qui si legge col titolo Rimbaud, l'altro se stesso, «ha aggiunto alla sua propria criptazione di messaggi sotto le vesti di un testo pubblico o privato il peso di un sorriso di ironica intelligenza» (p. 9). Incoraggiati da simili e altre prestigiose premesse, nonché da vari esperimenti tentati dal Surrealismo, i due autori si sono audacemente avventurati nella via attestata da questo curioso e anche, in certo senso, suggestivo, oltre che inusitato, libriccino, convinti appunto che nei poeti esista un doppio testo, uno riduttivo cercato dalla «tradizionale attività critica di esplicazione o addomesticamento» (p.14) e un altro, segreto, che non altera né spiega il primo, una seconda verità testuale, quella ritenuta nascosta e "vera", rivelata «attraverso la decrittazione o piuttosto ricomposizione per anagramma» (p. 10). Così, Bruno Pompili e Cosimo Amantonico (ma è quest'ultimo a essere esplicitamente riconosciuto l'iniziatore e l'inventore dell'impresa) hanno cercato di rivelarci il secondo testo, l'opera che si celerebbe ne Les Illuminations, cominciando ad esempio con l'anagrammarne il titolo in l'illusion en tamis (traduzione: l'illusione come vaglio). È infatti loro convinzione, dice Pompili, che Rimbaud «ha costruito una vita in parole, non in copia ma in alternativa alla realtà» (p. 15) e che «ha operato un travestimento estremo della persona, delle sue esperienze, del raffinato gioco di allusioni spesso interrotte o tarpate, modificate o selezionate» (p. 17). Per parte sua, Amantonico, che è autore del recente libro Metodo $e$ 
poesia in Mallarmé e al quale, a introduzione del suo lavoro diagrammatico, qui si deve il saggio dal titolo A Rimbaud. Atto dovuto, formula nel seguente modo il significato della ricerca applicata a Illuminations: "L'ipotesi che facciamo è di un'autobiografia scritta dalla quale il poeta avrebbe tratto materiale utile da disporre secondo una struttura reticolato o griglia - i diagrammi - per ricavarne ogni volta dei testi. Parliamo di una biografia scritta ma non di un'opera continua e conclusa. La biografia di pugno del poeta sarebbe stata una serie di flash, senza criterio cronologico, utili solo a comporre diversi testi della raccolta» (p.34). A ciò fa seguito per un centinaio di pagine una nutrita serie di proposte anagrammatiche su testi tratti appunto da Illuminations, proposte sul cui risultato, tuttavia, non è in alcun modo possibile esprimersi. Pur comprendendo l'alto grado di gratificazione di un simile gioco dal carattere inevitabilmente arbitrario (anche se in qualche caso, magari, perlustrativo), credo che sia necessario osservare che la critica "di esplicazione del testo» comunemente e variamente praticata non sempre può essere considerata, come afferma Pompili, di «addomesticamento» dello stesso. Con i suoi umili mezzi e senza inventare nulla, il critico può fondatamente e produttivamente indagare sul senso del nonsenso, sulla forma dell'informe, può accertare col massimo rispetto del testo che nella sua opera Rimbaud ci accompagna concretamente al di fuori delle coordinate della concettualizzazione occidentale, anche al di fuori della temporalità linguistica, poiché ciò che a lui importa sopra ogni cosa è «trouver une langue»e, insomma, su indicazione di Baudelaire, esplorare l'ignoto. 